\title{
EVALUATION OF THE OUTCOME OF PROXIMAL FEMORAL LOCKING COMPRESSION PLATE FOR THE TREATMENT OF COMMINUTED TROCHANTERIC AND SUBTROCHANTERIC FEMORAL FRACTURES IN LATERAL DECUBITUS APPROACH WITHOUT PEROPERATIVE IMAGE INTENSIFIER
}

HOSSAIN MMํ, ALAM QS ${ }^{2}$, QUASHEM FH³ ${ }^{3}$ NOMAN MTI ${ }^{4}$

\begin{abstract}
Introduction: The Comminuted trochanteric and subtrochanteric femoral fractures are considered as one of the most difficult fractures to treat in the orthopaedic surgery and they associated with high incidence of nonunion, malunion. Various implants, both intramedullary and extramedullary, are available for their fixation.
\end{abstract}

Objective: To assess the success rate of proximal femoral locking compression plate osteosynthesis in comminuted trochanteric and subtrochanteric femoral fracture in lateral decubitus approach without per operative image intensifier.

Method: 20 consecutive patients with comminuted Trochanteric and subtrochanteric fractures were operated upon with PF-LCP. Detailed clinical conditions of all patients, duration of operation, technical difficulty with the implant, hospital stay period were recorded. Patients were visited at 6 weeks interval till union then 3 monthly. The Harris Hip Score was used to document hip function at final follow-up.

Result: There were fifteen excellent (75\%), two good (10\%), two fair (10\%) and one poor (5\%) results according to Harris hip score. No instance of implant failure was recorded.

Conclusion: Fixation of comminuted subtrochanteric fractures with PF-LCP in lateral decubitus approach without per operative image intensifier provides stable fixation with high union rate and fewer complications.

Keywords: Proximal femoral locking compression plate, Femoral Comminuted trochanteric and subtrochanteric fracture, plate osteosynthesis, in lateral decubitus approach, without per operative image intensifier

J Dhaka Med Coll. 2014; 23(2) : 179-185.

\section{Introduction:}

Trochanteric and subtrochanteric femoral fractures account for $10 \%$ to $34 \%$ of all hip fractures. They have a bimodal age distribution and different mechanism of injury. Older patients typically sustain low-velocity trauma, where as in younger patients these fractures commonly result from high-energy trauma and often are associated with other fractures and injuries. (Lavelle, 2008).

Comminuted Trochanteric and subtrochanteric femoral fractures are high-energy injuries in adults. In the proximal part of the femur the medial cortex is subjected to compressive loads and the lateral cortex to tensile forces during weight bearing. Comminution of medial cortex

1. Dr. Md. Mobarak Hossain, Assistant Professor (Arthroplasty Orthopaedic Surgery)

2. Dr. Fazlul Haque Qasem, Assistant Registrar, Orthopaedic Surgery, Dhaka Medical College Hospital. Bangladesh.

3. Dr. Quazi Shahidul Alam, Assistant Professor Orthopaedic Surgery, Dhaka Medical College Hospital. Bangladesh. 4. Dr. MTI Noman, Assistant Registrar, Orthopaedic Surgery, Mymensingh Medical College Hospital. Bangladesh. Correspondence: Dr. Mobarak Hossain. Assistant Professor (Arthroplasty Orthopaedic Surgery), Dhaka Medical College Hospital. Bangladesh, Tel=+88-01715784628, E-mail. mobarak28@gmail.com 
may lead difficulty in anatomic reconstruction of this area. The blood supply of the comminuted fragments may be compromised in subtrochanteric region with predominantly cortical bone which has less healing capacity than metaphyseal region. Therefore, one should consider the biomechanics of mechanism of injury and preoperative plan for stability based on those assumptions. (Kayali, et al., 2008)

The management of these fractures is challenging for 2 reasons: (1) the inherent instability of the fracture pattern and (2) the forces of the muscles acting on the proximal and distal fragments. Fracture patterns at the subtrochanteric level are typically transverse or run obliquely in an inferolateral direction from the lesser trochanter. Thus, the fracture line runs parallel to the direction of movement of the lag screw in a sliding hip screw (SHS) implant, rendering this implant ineffective. Often, the medial calcar is comminuted, giving the fracture a tendency to collapse into varus. Medial comminution and the strong pull of the adductor musculature promote medialization of the shaft. The powerful abductor and iliopsoas muscles insert on the proximal fragment and force it into abduction, flexion, and external rotation. This makes closed reduction of this fracture difficult and pushes the proximal fragment into a malreduced position. (Kuzyk, et al., 2009)

Over the last few years, there has been a shift in the principles of management of these fractures from rigid anatomic reduction to relative biological fixation which preserves the vascularity of bone fragments and enhances their callus-forming abilities. Biological fixation, in comparison to traditional open plating, has produced good results for these fractures. (Saini, et al., 2013)

The proposed three requirements for an ideal internal fixation for pertrochanteric fracture: (1) femoral neck screw with at least three dimensional structures of the fixed system; (2) minimal angle between the femoral neck screw axis and the femoral shaft and thus maximum alignment between the angle of normal hip joint weight-bearing line and the femoral graft axis and (3) ability of the implant to prevent the rotation of the femoral head. Unfortunately, none of the currently used devices can fully meet these three criteria. Future studies should be conducted to determine the optimal implant for the internal fixation of pertrochanteric fractures that can maximally meet the three criteria described above. (Zha, et at., 2011).

\section{Method:}

This is a prospective interventional study (Quasi experimental type) done From December 2013 to May 2014 at department of Orthopaedic Surgery, DMCH. All patients with clinical and radiological evidence of comminuted trochanteric and subtrochanteric fracture admitted in Hospitals for operation within three weeks of incidence. Active or latent infection, Pathological fracture other than osteoporotic fracture, Open fracture, Non-united fracture were excluded from the study.

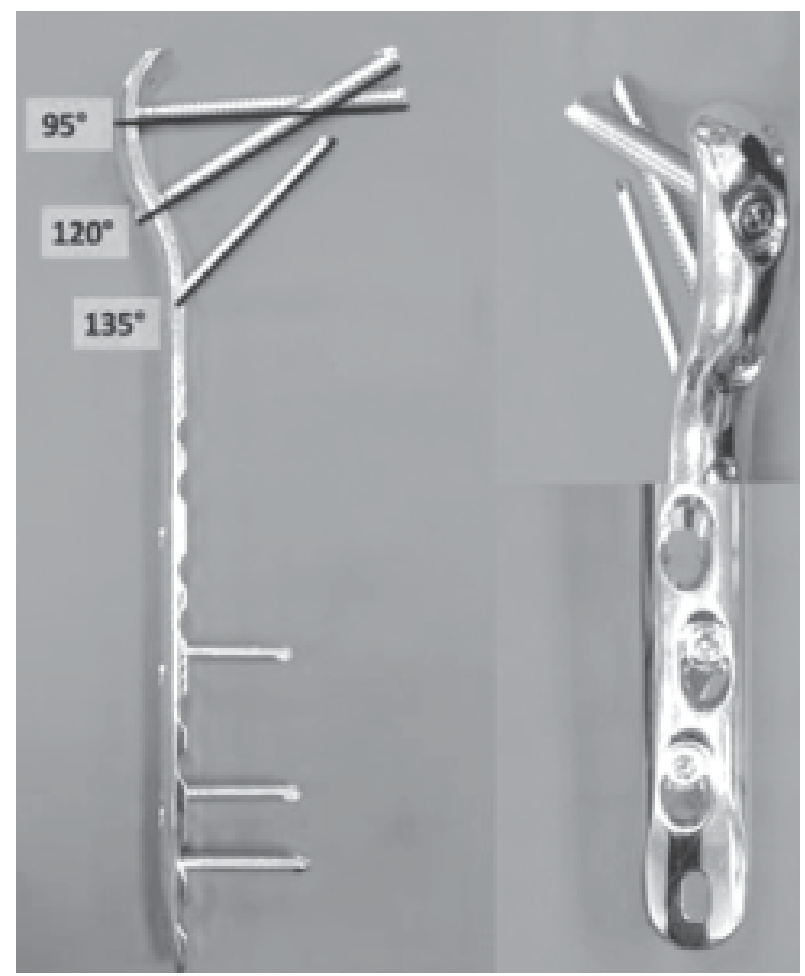

Fig.-1: The locking compression plate for the proximal femur is a precontoured, angular stable, with large fragment screw (7.3/5.0/4.5mm). 
Surgery was performed with the patient in lateral position in a normal operating table (not in a fracture table). Length restoration and fracture reduction was done by open method. A lateral approach typically is performed by a straight incision from the greater trochanter, extending approximately $10 \mathrm{~cm}$ distally. The proximal fragment is first fixed to the plate, and the plate is then reduced to the femoral shaft. After ensuring perfect anatomic placement of the plate to the proximal fragment, a $2.5-\mathrm{mm}$ drill tip guide wire is inserted through a wire sleeve that is threaded to the most proximal hole at a predetermined $95^{\circ}$ angle. A second guide wire is then inserted through the drill sleeve of the second hole in a $120^{\circ}$ angle. Finally, a third guide wire is inserted through the sleeve on the third hole above the calcar in a $135^{\circ}$ angle. The plate was then distally fixed with bicortical locking head screws. After proper haemostasis a drain was placed at appropriate site and wound was closed in layers. The skin was closed with skin stapler.

\section{Results:}

The patients started static quadriceps exercises after 24 hours. Drain tube was removed after 48 hours. Stitches were removed on $14^{\text {th }}$ postoperative day. Postoperatively antibiotics were given routinely for 2 weeks. The Patients was allow moving out of bed using crutch and without bearing weight on operated limb as pain permits. Knee bending was allowed as pain permits. The patients was discharged with the advice to walk on crutch non - weight bearing on affected side for 6 weeks and then to report to the outpatient department. Partial weight bearing was allowed as soon as the patient could tolerate it with considering the fracture configuration, bone quality and the stability of the fixation. Full weight bearing was started when the fracture showed complete union clinically by absence of limb pain when standing upon the fracture limb alone and radiologically by the presence of the abundant callus at least in two views.
Table- I

Distribution of patient according to bony union time

\begin{tabular}{lccc}
\hline \multicolumn{4}{c}{$\begin{array}{c}\text { Evidence of bony union shown on plain } \\
\text { radiograph }\end{array}$} \\
$\begin{array}{l}\text { Time } \\
\text { (weeks) }\end{array}$ & $\begin{array}{c}\text { Number of } \\
\text { patients }\end{array}$ & $\begin{array}{c}\text { Percentage } \\
(\%)\end{array}$ & $\begin{array}{c}\text { Mean } \\
\pm \text { SD }\end{array}$ \\
\hline $12-18$ & 16 & 80 & $17.79 \pm 2.89$ \\
$19-24$ & 02 & 10 & \\
$25-30$ & 02 & 10 & \\
\hline
\end{tabular}

Among 20 patients mean time to union was $17.79 \pm 2.89$ weeks. Four cases were of delayed union.

Table-II

Postoperative complication

\begin{tabular}{lcc}
\hline $\begin{array}{l}\text { Postoperative } \\
\text { complication }\end{array}$ & $\begin{array}{c}\text { No. of } \\
\text { patient }\end{array}$ & $\begin{array}{c}\text { Percentage } \\
(\%)\end{array}$ \\
\hline Infection & 1 & 5 \\
Screw cutout & 0 & 0 \\
Implant failure & 0 & 0 \\
Limb shortening $1 \mathrm{~cm}$ & 2 & 10 \\
\hline
\end{tabular}

Postoperative complications were minimum.

Table-III

Comparison of ROM and SNA

\begin{tabular}{lccc}
\hline Outcome & $\begin{array}{c}\text { Injuried Hi } \\
(\text { Mean } \pm \text { SD) }\end{array}$ & $\begin{array}{c}\text { Healthy Hip } \\
(\text { Mean } \pm \text { SD) }\end{array}$ & $\begin{array}{c}\text { P- } \\
\text { value }\end{array}$ \\
\hline $\begin{array}{l}\text { Range of } \\
\text { Motion }\end{array}$ & $139.47 \pm 4.04$ & $142.37 \pm 2.57$ & $\mathrm{p}>.05$ \\
$\begin{array}{l}\text { Shaft Neck } \\
\text { Angle }\end{array}$ & $133.58 \pm 1.07$ & $134.32 \pm 0.94$ & $\mathrm{p}>.05$ \\
\hline
\end{tabular}

Range of Motion and Shaft Neck Angle of the hip joint of the injured and healthy side were measured at the last follow-up. Paired t- test was done for calculation of test statistic and there was no significant difference between them $(\mathrm{p}>0.05)$.

\section{Harris Hip Score:}

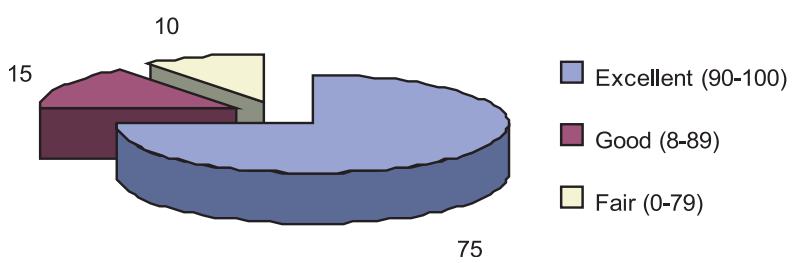

Chart-1: Harris Hip Score

Mean Harris Hip Score was 92.05 \pm 7.85 . 
Table- IV

Distribution of the results according to the final outcomes $(n=20)$

\begin{tabular}{lcc}
\hline Result & $\begin{array}{c}\text { Number of } \\
\text { patient }\end{array}$ & Percentage \\
\hline $\begin{array}{l}\text { Satisfactory } \\
\text { (Excellent \& Good) }\end{array}$ & 18 & $90 \%$ \\
$\begin{array}{l}\text { Unsatisfactory } \\
\text { (Fair \& Poor) }\end{array}$ & 02 & $10 \%$ \\
\hline Total & 20 & $100 \%$ \\
\hline
\end{tabular}

\section{Case-1}

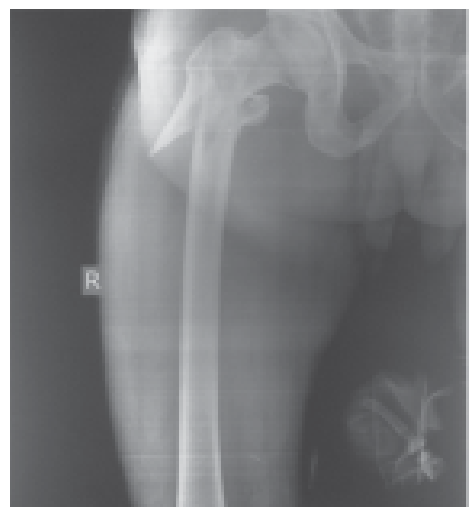

Pre-operative x-ray on 25/ $03 / 2014$

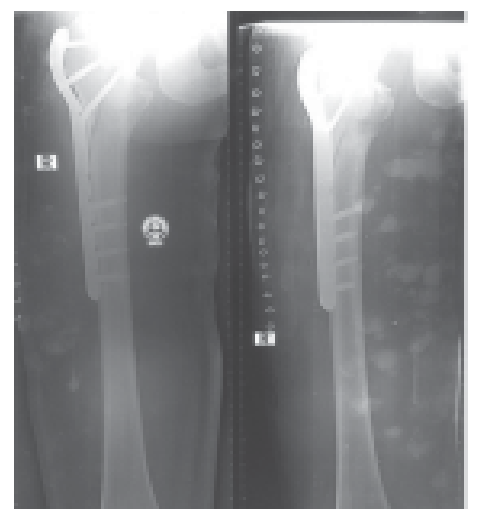

Post operative x-ray on 20/ $04 / 2014$
Confidence level of the final outcome:

Confidence interval $(\mathrm{CI})=\mathrm{P}+1.96 \sqrt{\frac{\mathrm{pq}}{\mathrm{n}}}$ ( $95 \%$ confidence level) here, $\mathrm{p}=85, \mathrm{q}=(100-85)=15, \mathrm{n}=20)$

$$
\begin{aligned}
& \text { So, } \mathrm{Cl}=85+1.96 \sqrt{\frac{85 \times 15}{20}} \\
& =85+16.64 \\
& =69.36-100.64
\end{aligned}
$$

So, among the population we will find almost $70 \%$ to $100 \%$ satisfactory result by this procedure. It is quite acceptable outcome.

\section{Case-2}

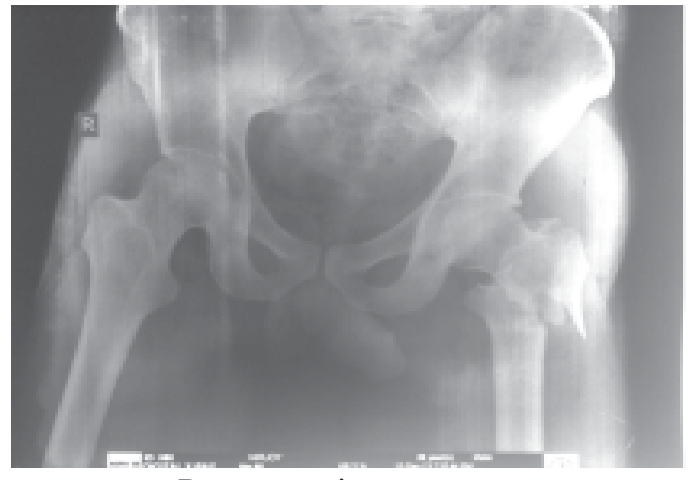

Pre-operative $\mathrm{x}$-ray on

Case-3

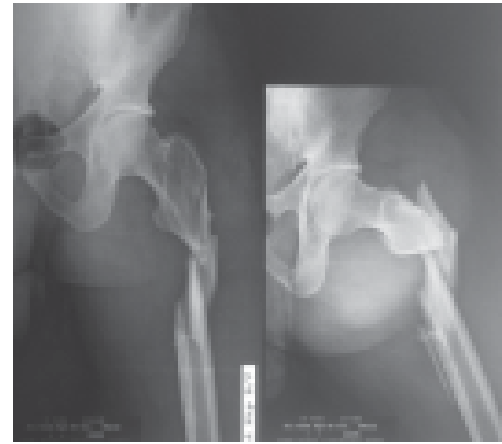

Pre-operative $\mathrm{x}$-ray on $20 / 05 / 2014$

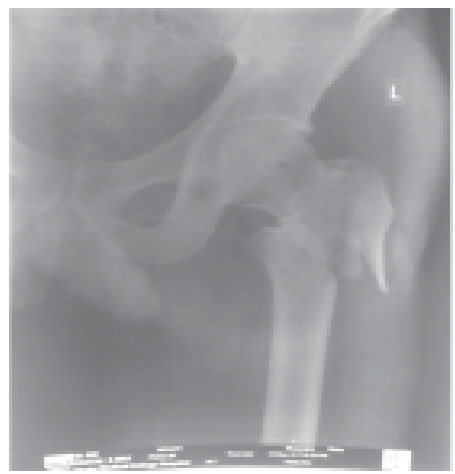

Pre-operative $\mathrm{x}$-ray on $12 / 10 / 2013$

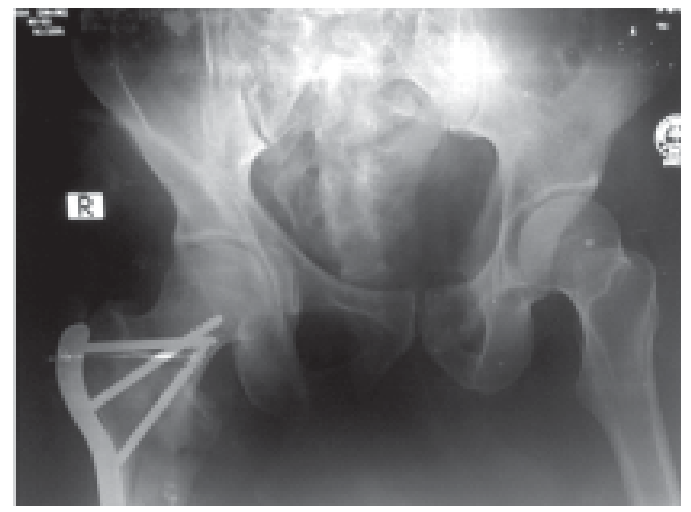

Post operative $\mathrm{x}$-ray on 20/04/2014 


\section{Discussion}

Comminuted Trochanteric and subtrochanteric femoral fractures are considered as one of the most difficult fracture to treat for the orthopaedic surgeons. It was found that indirect reduction and biological fixation method with the dynamic condylar screw and plate is considered as a valuable cheap fixation method for the management of comminuted subtrochanteric fractures of femur especially in the young patient's populations. (Elzohairy, 2012).

In our study we evaluated the result of proximal femoral locking compression plate osteosynthesis in lateral decubitus approach without per operative image intensifier for the treatment of comminuted Trochanteric and subtrochanteric fracture and we did a prospective study. lateral positioning neutralizes the gravitational forces acting on the bone and soft tissues, facilitating reduction and exposure which inturn provide as a technical trick for anatomic and stable reduction of complex proximal femur fractures with proximal femoral locking plates. (Connelly And Archdeacon, 2012). Out of our 20 patients, age range from 21-70 years with a mean age of 41.35 years. Among them maximum were between 31-40 years (35\%). From June 2009 to December 2010, a similar study was done in the Department of Orthopaedics and Traumatology, Tire State Hospital, Izmir, Turkey by Kayali, et al., (2008), where the mean age was 46 years (29-76 years).

Like all trauma cases comminuted Trochanteric and subtrochanteric fracture is more common in male due to more activities and traveling. In a study of comminuted subtrochanteric fracture by Saini et al, (2013) male patients were $87.5 \%$. In our study, out of 20 patients, male patients were 17 (85\%).

High velocity trauma due to road traffic accidents was the main cause of these fractures seen in our study similar to a study in Department Of Orthopaedic Surgery, Chung Gung Memorial Hospital Taoyuan, by Lee, et al., 2002.

The mean duration of follow up was 39.70 weeks (24-58 weeks). Average time to union was 17.35 weeks (14-28 weeks). In a study conducted at the Department of Orthopaedics, Swami Man Singh Medical College and Hospital, India, by Saini et al, (2013), the mean duration of follow up was 40.25 weeks, and time to union was 16.2 weeks. Partial weight bearing $(15-20 \mathrm{~kg})$ was allowed as soon as the patient could tolerate it and full weight bearing was started when the fracture showed complete union clinically by absence of limb pain when standing upon the fracture limb alone and radiologically by the presence of the abundant callus at least in two views. Bone union was defined as callous formation at the fracture site, with the fracture line visible for less than a quarter of the circumference (Lee, 2002) and as painless full weight bearing clinically (Kayali, 2008). Sixteen patients had union within 18 weeks, two patients had union within 24 weeks, and 2 patients had delayed union (28 weeks). One centimeter shortening was seen in two patients. No patient had significant rotational malalignment as determine by clinical examination. There were no cut-outs, breakage or pull-out of screws. A similar study of fixation of comminuted proximal femoral fracture in Orthopaedic Department $\mathrm{CMH}$, Lahore, from October 2009 to September 2010, with 29 patients by Bukhari and Ashgar, (2011), in which one patient developed nonunion.

Shaft-neck angle and range of motion of hip joint of the injured and healthy sides were measured at the last follow up, and there was no significant difference between them ( $p>0.05$ ). Another study done by Kayali, et al., (2008) in the Department of Orthopaedics and Traumatology, the state Hospital Izmir, Turkey also evaluated no significant differences between injured and healthy hip movements and SNA.

Harris Hip Score was used for clinical assessment, as per Harris Hip Score 18 patients $(90 \%)$ had good or excellent outcome with two fair result $(10 \%)$, which was similar to the outcome of the study of Siani et al, (2013).

\section{Conclusion :}

The present study conclude, with proper patient selection, good instrumentation and surgical technique, proximal femoral locking 
compression plate is the implant of choice in the management of comminuted Trochanteric and subtrochanteric fracture.

Large scale studies with longer follow up are essential requirement for an optimum outcome measurement. Though the study was small which may not represent the whole scenario but the results of the study can be utilized for future large study.

\section{References}

1. Anglia Ruskin University Library, 2011. Guide to the Harvard Style of Referencing, $3^{\text {rd }}$ edition, [PDF] London. Anglia Ruskin University. Available at:

2. <http://libweb.anglia.ac.uk/referencing/ harvard.htm> [Accessed 29 March 2012]

3. Baumgaertner, M.R., Curtin, S.L., M.D.T., Lindskog, D.M., Keggi, J.M., 1995. Value of the Tip-Apex Distance in Predicting Failure of Fixation of Peritrochanteric Fractures of the Hip. The Journal of Bone \& Joint Surgery, 77-A, pp. 1058-64.

4. Bergman, G.d., Winquist, R.A., Mayo, K.A., Hansen, S.T., 1987. Subtrochanteric fracture of the femur fixation using the Zickel nail. The Journal of Bone and Joint Surgery, 69-A, pp. 1032-40.

5. Boyd, H.B., and Griffin, L.L., 1949. Classification and treatment of trochanteric fractures. Archives of Surgery, 58, pp.853-866.

6. Bridle, S.H., Patel, A.D., Bircher M, Calvert PT., 1991. Fixation of intertrochanteric fractures of the femur-a randomised prospective comparison of the gamma nail and the dynamic hip screw. The Journal of Bone \& Joint Surgery, 73-B, pp. 330-34.

7. Bukhari, S.A.H., Asghar, A., 2011. Dynamic Condylar Screw Fixation for Comminuted Proximal Femur Fractures. Journal of Surgery Pakistan (International), 16 (4), pp.149-52

8. Celebi L., Can, M., Muratli, H.H., Yagmurlu, M.F., Yuksel, H.Y., Bicimoglu, A., 2006. Indirect reduction and biological internal fixation of comminuted subtrochanteric fractures of the femur. Injury International Journal of the Care of the Injured, 37(8), pp.740-50.

9. Collado, F., Vila. J And Beltran, J. E., 1973. Condylo-cephalic nail fixation for trochanteric fractures of the femur. The Journal of Bone \& Joint Surgery, 55-B, pp. 774-79.

10. Connelly, C.L. And Archdeacon, M.T., 2012. The lateral decubitus approach for complex proximal femur fractures: anatomic reduction and locking plate neutralization: a
11. technical trick. Journal of orthopeedic trauma, 26(4):252-7.

12. Crist B.D., Khalafi A., Hazelwood, S.J., Lee, M.A., 2009. A biomechanical comparison of locked plate fixation with percutaneous insertion capability versus the angled blade plate in a subtrochanteric fracture gap model. Journal of Orthopaedic Trauma, 23, pp.622-27.

13. Egol, K.A., Kubiak, E.N., Fulkerson, E., Kummer, F.J., Koval, K.J., 2004. Biomechanics of locked plates and screws. J Orthop Trauma, 18, pp. 48893.

14. Elzohairy, M.M., 2012. Management of Comminuted Subtrochanteric Femur Fractures by Indirect Reduction and Biological Fixation with Dynamic Condylar Screw. J Trauma Treat, 1, pp.1-3

15. Forward, D.P., Doro, C.J., O’Toole, R., Kim, H., Floyd, J.C., Sciadini, M.F., 2012. Biomechanical comparison of a locking plate, a nail and a $95^{\circ}$ angled blade plate for fixation of

16. subtrochanteric femoral fractures. Journal of Orthopaedic Trauma, 26, pp.334-40.

17. Floyd, J. C. P., O'Toole, R.V., Stall, A., Forward, D.P. Nabili, M., Shillingburg, D., Hsieh, A., and Nascone, J.W., 2009. Biomechanical Comparison of Proximal Locking Plates and Blade Plates for the Treatment of Comminuted Subtrochanteric Femoral Fractures. J Orthop Trauma , 23, pp.62833.

18. Goodman, R.S., 2011. Intertrochanteric Hip Fractures. [online]. Medscape Refrance: Drugs, Diseases \& Procedure. Available at: > http:// emedicine.medscape.com/article/1247210overview> [Accessed 29 March 2012]

19. Hasenboehler, E.A., MD; Agudelo, J.F., Morgan, S.J., Smith, W.R., Hak, D.J., Stahel, P.F., 2007. Treatment of Complex Proximal Femoral Fractures with the Proximal Femur Locking Compression Plate. Othopaedics, 30(8). pp.618-23.

20. Haidukewych, G. J., 2004. Innovations in Locking Plate Technology. Journal of the American Academy of Orthopaedic Surgeon, 12, pp.205-12.

21. Kayali, C., Agus, H., Zincircioglu, G., 2008. The Role of Biological Fixation with Bridge Plating for Comminuted Subtrochanteric Fractures of the Femur. Turkish Journal of Trauma \& Emergency Surgery, 14(1), pp.53-58

22. Kuderna, H., Bohler, N And Collon, D. J. 1976. Treatment of Intertrochanteric and Subtrochanteric Fractures of the Hip by the Ender Method. The Journal of Bone \& Joint Surgery, 58-A, pp. 604-11. 
23. Kuzyk, P.R.T., Bhandari, M., McKee, M.D., Russell, T.A., Schemitsch, E.H., 2009. Intramedullary Versus Extramedullary Fixation for Subtrochanteric Femur Fractures. J Orthop Trauma, 23, pp.465-70

24. Kyle, R.F., 1993, Fracture of the hip. In R.B. Gustilo, R.F. Kyle and D. C. Templeman, eds. 1993. Fractures and Dislocations, volume 2, St. Louis, Mosby, Ch.23, pp. 783-854.

25. Lavelle, D.G. 2008. Fracture and Dislocation of the Hip. In: S.T. Canale and Beaty J. H. eds. 2008. Campbell's Operative Orthopaedics, Volume III: $11^{\text {th }}$ Ed. Philadelphia, PA: Mosby, Elsevier, Ch. 52. pp. 3237-309.

26. Lee, P.C., Yu, S.W., Hsieh, P.H., Su, J.U., Chen, Y.J., 2002. Bridge-Plating Osteosynthesis of 20 Comminuted Subtrochanteric Fractures with Dynamic Hip Screw. Chang Gung Med J, 25, pp.803-10

27. Mahadevan, V., 2008. Pelvic girdle and lower limb. In: S. Standring, ed.2008. Gray's anatomy, $40^{\text {th }}$ ed. Churchill Livingstone: Elsevier. Sec. 9, pp. 1327-1464

28. Murray, R.C., Frew, J.F.M., 1949. Trochanteric fractures of the femur, a Plea for Conservative treatment. The Journal of Bone \& Joint Surgery, 31-B, pp.204-19.,

29. Purushothaman, K., Devalia, k., Rankin, S., Hazurika, P., Bansal, A.N., 2011. Proximal femoral locking plate for complex proximal femur fractures-Early result from two centers. Abstracts/ Injury Extra, 42, PP. 95-169.

30. Saini, P., Kumar, R., Shekhawat, V., Joshi, N., Bansal, M., Kumar, S., 2013. Biological fixation of comminuted subtrochanteric fractures with proximal femur locking compression plate. Injury International Journal of the Care of the Injured, 44, pp.226-31
31. Sarmiento, A., 1963. Intertrochanteric fractures of the femur, $150^{\circ}$ angle nail plate fixation and early rehabilitation. The Journal of Bone \& Joint Surgery, 45-A, pp.706-22.

32. Schipper, I.B., Steyerberg, E. W., Castelein, R. M., Heijden, V.D., Hoed, P.T., Kerver, A.J.H, Vugt, A.B., 2004. Treatment of unstable trochanteric fracture - Randomised Comparison of the Gamma Nail and the Proximal Femoral Nail. The Journal of Bone \& Joint Surgery, 86-B, pp.86-94.

33. Seinsheimer, F., 1978. Subtrochanteric Fractures of the Femur. The Journal of Bone \& Joint Surgery, 60-A, pp. 300-06.

34. Strauss, E.J., Schwarzkopf, R., Kummer, F., Egol, K.A., 2008.The Current Status of Locked Plating: The Good, the Bad, and the Ugly. J Orthop Trauma, 22, pp. 479-86.

35. Synthes, 2007. LCP Proximal Femoral Plate 4.5/ 5.0: Technique Guide. [pdf] Oberdorf. Available at: <http://synthes.vo.11nwd.net/Synthes $\% 20$ International/KYO/Trauma/ PDFs/ 036.000.403.pdf> [Accessed 29 March 2012]

36. Zha G.C., Chen Z.L., Qi X.B., Sun J.Y., 2011. Treatment of pertrochanteric fractures with a proximal femur locking compression plate. Injury International Journal of the Care of the Injured, 42, pp.1294 - 99.

37. Zhou, F., Zhang, Z., Yang, H., Tian, Y., Ji, H.Q., Guo, Y., 2012. Less invasive stabilization system (LISS) versus proximal femoral nail anti-rotation (PFNA) in treating proximal femoral fractures: a prospective randomized study. Journal of Orthopaedic Trauma, 26, pp. 155-62.

38. Zickel, R.E., 1976. An Intramedullary Fixation Device for the Proximal Part of the Femur-nine years experience. The Journal of Bone \& Joint Surgery, 58-A, pp.866-72. 